\title{
The impact of the repeal of the federal individual insurance mandate on uninsurance
}

\author{
Aparna Soni ${ }^{1}$ (ID
}

Received: 9 July 2021 / Accepted: 25 January 2022 / Published online: 1 March 2022

(c) The Author(s), under exclusive licence to Springer Science+Business Media, LLC, part of Springer Nature 2022

\begin{abstract}
The federal individual mandate of the Affordable Care Act, which required people to pay a tax penalty if they did not have health insurance, was repealed in 2019. However, some states implemented state-level insurance mandates which essentially replaced the federal mandate. I use nationally representative survey data from the 2015-19 Annual Social and Economic Supplement to the Current Population Survey to compare the probability of becoming newly uninsured among people living in states without state-level insurance mandates versus states with a mandate, before and after the 2019 repeal. In a sample of 214,821 lower-income, nonelderly adults, the repeal of the federal mandate was associated with a $0.5 \%$ point, or $24 \%$, increase in the year-over-year probability of becoming newly uninsured. These results suggest that people respond to financial incentives when making insurance enrollment decisions. In the absence of a federal mandate, state-level mandates may reduce transitions to uninsurance.
\end{abstract}

Keywords Insurance $\cdot$ Individual mandate $\cdot$ Affordable Care Act

JEL Classification I13

\section{Introduction}

An original provision of the Affordable Care Act (ACA) imposed a tax penalty on uninsured individuals. The provision, commonly known as the "individual mandate," intended to increase insurance coverage and reduce adverse selection by incentivizing healthier people to enroll (Fiedler, 2020). However, the mandate's opponents viewed it as “.... stunning assault on liberty" and an attempt to "...trample on the freedoms of Americans" (Young, 2009). New tax legislation (the Tax Cuts and Jobs Act of 2017) effectively repealed the

Aparna Soni

asoni@american.edu

1 School of Public Affairs, American University, 4400 Massachusetts Avenue NW,

20016 Washington DC, USA 
mandate starting in January 2019. Although the federal mandate was repealed, five states (California, Rhode Island, Vermont, Massachusetts, and New Jersey) and the District of Columbia implemented state-level individual insurance mandates, which essentially replaced the federal mandate. ${ }^{1}$ Consequently, as of January 2019, uninsured residents of states with state-level mandates were still subject to a tax penalty, whereas those in the remaining states did not face a penalty for being uninsured.

Previous studies have established the effectiveness of the ACA's individual mandate as a mechanism to increase health insurance coverage. The implementation of the individual mandate increased insurance rates, particularly among healthier people who-without the mandate - are less likely to purchase insurance if the cost of insurance exceeds their expected health care spending (Fiedler, 2018; Jacobs, 2018; Lurie et al., 2021; Saltzman, 2019). Lurie et al. (2021) show clear and statistically significant discontinuities in coverage corresponding to the discontinuities in the mandate penalty, which suggests that the penalty affects people's coverage decisions. They find that men, young adults, and low-income people are especially responsive to the penalty. Saltzman (2019) studies the California and Washington ACA exchanges and concludes that while there is a limited response to the amount of the mandate penalty, there is a significant response to the existence of a mandate, suggesting that people have "a taste for compliance." Focusing on a sample with family incomes above $400 \%$ of the poverty level, Fiedler (2018) concludes that the individual mandate accounts for most of the post-ACA decline in the uninsured rate among people in this income group. Similarly, Jacobs (2018) focuses on higher-income adults and exploits pre2014 state differences in the non-group insurance market; the study finds that the individual mandate reduced uninsurance by 19 to $30 \%$ in this income group.

Conceptually, it follows that repealing the mandate may increase uninsurance by reducing people's financial cost of being uninsured. Since insurers are barred from varying premiums based on health status, healthier people may prefer uninsurance if premiums exceed their expected health spending. Simulation models predicted that the number of uninsured people would increase by 7 million between 2019 and 2029, but there has been little empirical analysis of the effects of the mandate repeal (Congressional Budget Office, 2019). Others have pointed to a correlation between the timing of the mandate repeal and a nationwide rise in uninsurance (Keith, 2020), but observational studies cannot isolate the impact of the repeal from other concurrent policies and events. To date, we know little about the causal effect of the repeal on insurance coverage.

This study fills that gap by implementing a quasi-experimental difference-in-differences regression design. Using 2015-2019 Current Population Survey data that provides insurance status for the same individuals across two years, I compare the probability of becoming newly uninsured for individuals living in states with no state-level insurance mandates versus states with mandates, before and after the federal mandate was repealed in January 2019. I find that the repeal of the federal mandate resulted in a $0.5 \%$ point increase in the probability of becoming newly uninsured among a sample of lower-income, nonelderly adults. This result is robust to several specification checks and sensitivity analyses, including controlling for state labor market conditions and using alternate sets of treatment and control groups. Tests of pre-policy parallel trends and falsification tests support a causal

\footnotetext{
${ }^{1}$ Of these six jurisdictions, only three (MA, NJ, and DC) implemented insurance mandates during my study period (2015-2019). The remaining three states (CA, RI, and VT) did not implement mandates until 2020, so these three states are considered non-mandate states for the purpose of this study.
} 
interpretation of the results. These findings provide policy-relevant guidance for states that have enacted or are considering enacting their own mandates.

\section{Data}

I examine data from the 2015-2019 Current Population Survey's Annual Social and Economic Supplement (CPS ASEC) (Flood et al., 2020). The survey was conducted between February and April each year and provides data on respondents' insurance coverage, state of residence, and socio-demographic characteristics. I restrict the analytical sample to nonelderly adults with household incomes between 138 and $400 \%$ of the poverty level $(N=214,821)$. I omit lower income respondents because their eligibility for Medicaid under the ACA was unaffected by the mandate repeal and because individuals whose income falls in this range are exempt from the state-level individual mandate penalty in Massachusetts. Similarly, I omit higher-income individuals who have widespread access to employer-sponsored insurance and are also unlikely to be affected by the mandate repeal. Appendix Table A1 presents demographic characteristics of the sample.

My outcome variable of interest, "Newly Uninsured," is equal to 100 if the respondent was insured in the last calendar year but uninsured at the time of interview and equal to 0 otherwise. To construct this variable, I first generate a variable called "Any Coverage Last Year." This is a binary variable indicating whether the respondent had any of the following sources of insurance coverage during the previous calendar year: Medicaid, Medicare, the VA's CHAMP program, Tricare, SCHIP, private health insurance, or any other government health insurance coverage. I then identify the IPUMS CPS variable indicating whether the respondent was covered by any type of health insurance at the time of interview. I construct the variable "Newly Uninsured" as an indicator equal to 1 for respondents who had some source of insurance coverage last year but did not have any coverage at the time of interview. The "Newly Uninsured" variable is equal to 0 for all other respondents. Finally, I multiply the "Newly Uninsured" variable by 100 for ease of interpretation, so my final outcome variable ranges from 0 to 100 . Respondents who refused to answer the questions regarding insurance coverage are excluded from analysis.

Health insurance coverage is self-reported by respondents in the ASEC and is thus subject to misreporting. To reduce the probability of misreports, the ASEC's series of insurance questions was recently redesigned to make the survey more user-friendly and less prone to measurement error (Pascale, 2016; Pascale et al., 2016). Rather than asking a series of yes/ no questions on specific sources of insurance coverage, the survey asks individuals whether they are covered or not, then asks about the general source of coverage, and finally asks follow-up questions tailored to the respondent's specific sources of coverage. These changes were implemented before the start of my study period.

The ASEC is a well-recognized data source and has been used in previous published studies of health insurance (Abramowitz \& O'Hara, 2017; Kaestner et al., 2017; Wagner, 2015). Moreover, independent validations of the ASEC health insurance survey modules support the accuracy of the insurance measures (Pascale et al., 2019). For example, Pascale et al. (2019) finds that the ASEC overestimates the uninsured population only by $1.9 \%$ points, whereas the American Community Survey - another commonly-used data source in studies of health insurance — overestimates the uninsured population by $3.5 \%$ points. 


\section{Methods}

My empirical approach leverages variation in state-level implementation of insurance mandates. During the study period, two states (MA and NJ) and DC implemented statelevel mandates, so uninsured people in these states were subject to a tax penalty even after January 2019 (Porretta, 2021). ${ }^{2}$ The repealed ACA federal mandate imposed a tax penalty on uninsured individuals equal to the greater of $\$ 695$ or $2.5 \%$ of annual income; the penalty was capped at the price of the cheapest bronze plan. Similarly, in Massachusetts, New Jersey, and DC, the amount of the penalty varies by income, age, and family size and is linked to the plan premiums on the ACA health insurance exchanges. For example, in DC, uninsured individuals must pay either $2.5 \%$ of the gross family household income or $\$ 695$ per adult and $\$ 348$ for child; the maximum penalty is capped at the average premium for bronze-level health plans available on the DC health insurance exchange.

I compare uninsurance in states where the individual mandate was repealed (i.e. the treatment group) to states where the individual mandate was effectively not repealed due to state-level mandates (i.e. the control group). MA, NJ, and DC constitute the control group in this study, as residents of these states were subject to an insurance mandate during the entire study period. People in the remaining 48 states became exempt from any insurance mandate after the federal mandate was repealed in January 2019. These 48 states constitute the treatment group. Because the treatment group did not have state-level mandates in place, the repeal of the federal mandate was essentially binding in these states and residents were free to drop coverage without being subject to a tax penalty. States that implemented insurance mandates in 2020 or later (CA, RI, VT) are included in this set of treatment states (i.e. states where the repeal was binding) because my study period ends in 2019. In sensitivity analyses, I show that results are robust to the use of a smaller subset of treatment states.

I estimate a difference-in-differences (DD) regression model in which the outcome variable is "Newly Uninsured," and the key independent variable is the interaction of an indicator for whether the respondent lived in a treatment state and an indicator for whether the respondent was interviewed after January 2019, i.e. after the federal mandate was repealed. Equation (1) presents the preferred DD regression model:

$$
\text { Newly Uninsured }_{i s t}=\alpha+\beta \text { MandateRepealed }_{s} \text { X Post } 2019_{t}+\gamma \mathbf{X}_{\text {ist }}+\delta \text { State }_{s}+\theta \text { Year }_{t}+\varepsilon
$$

where Newly Uninsured $_{\text {ist }}$ is the probability (ranging from 0 to 100) that respondent $i$ in state $s$ was newly uninsured in the year of interview $t$; MandateRepealed $_{s}$ indicates whether the respondent lived in one of the 48 states without a state-level insurance mandate; Post $2019_{t}$ indicates whether the respondent was interviewed after January 2019, i.e. after the repeal of the federal insurance mandate; $\boldsymbol{X}_{i s t}$ is a vector of socio-demographic controls, including respondent's age, sex, marital status, household size, race/ethnicity, educational attainment, and employment status; State $_{s}$ is a vector of state fixed effects; Year ${ }_{t}$ is a vector of year fixed effects; and $\varepsilon$ is an idiosyncratic error term. Robust standard errors are clustered at the state level. Estimates include CPS ASEC survey weights.

2 Three other states (CA, RI, and VT) implemented insurance mandates in 2020. Because my study period ends in 2019 , I considered these three states non-mandate states for the purpose of my analysis. 
Observing the same respondent for two consecutive years helps control for unobserved individual-level characteristics and risk preferences. Controlling for respondents' state of residence accounted for time-invariant, unobserved differences across states, and controlling for the year of interview differences out nationwide trends in insurance coverage.

In Eq. (1), the coefficient $\beta$ represents the effect of the mandate repeal on the probability of being newly uninsured, assuming that the two key assumptions of the DD model are met. First, in the absence of the policy change, the treatment and control group would have trended similarly (the parallel trends assumption). Second, the treatment and control states did not undergo other differential changes at the same time of the policy change. I assess the validity of the first assumption by estimating an event study regression that assesses trends between the treatment and control states in the pre-2019 period. If the treatment and control groups followed parallel trends in the pre-repeal period, it would increase our confidence that they would have continued to trend similarly in the post-repeal period, were it not for the repeal. The event study model is similar to Eq. (1) but replaces the MandateRepealed X Post2019 interaction with a vector of terms that interacts MandateRepealed with indicator variables for each year. The year immediately preceding the federal mandate repeal (2018) is omitted as the base year.

To test the validity of the second DD assumption, I conduct two falsification tests by estimating Eq. (1) for groups of adults whose incentive to drop insurance coverage was likely unchanged by the mandate repeal: elderly adults (who were eligible for Medicare both before and after the repeal) and high-income adults (with household income above $600 \%$ FPL) who have widespread access to employer-sponsored insurance. Strong effects for either of these two groups could be an indication that simultaneous changes in other policies may be biasing my main set of results.

I conduct several sensitivity analyses and robustness checks. First, I control for state unemployment rate to account for differences in labor market conditions across states over time. I also estimate a set of regressions in which I include those below $138 \%$ of the poverty level in the analysis. There may be concern that the treatment group of states is larger and more diverse than the control group (MA, NJ, and DC). To address this concern, I present a specification check which restricts my analysis to states in the New England and midAtlantic Census divisions to provide a better geographical match between the treatment and control groups. I also estimate a regression that omits the year 2018 from analysis, as the repeal was announced in 2017 and some people may have falsely believed it would be implemented in 2018 (Fung et al., 2019).

I assess potential heterogeneous treatment effects by estimating the regression model separately for different subgroups of respondents: men and women, married and unmarried adults, parents and childless adults, by employment status, by educational attainment, by race/ethnicity, and by age group.

Next, I conduct placebo tests with outcome variables that should be theoretically unaffected by the mandate repeal-respondents' unemployment status, self-employment, labor force participation, and household income. Finding statistically significant effects of the mandate repeal on these outcomes implies that other policy changes occurring in the treatment or control group could be biasing the main set of results.

In my baseline model, I compare three control states to 48 treatment states, and I cluster standard errors by state. Because there are many more treated states than control states, over-rejection of the null hypothesis is a concern (Cameron et al., 2008; Ferman \& Pinto, 
2019). The specification check described above in which I limit my analysis to states in the New England and mid-Atlantic Census divisions partially addresses this concern. As another check, I calculate p-values using the wild cluster bootstrap resampling method with 999 replications, proposed by Cameron et al. (2008). This step produces approximately valid estimates for inference by allowing respondents to be dependent within states, relaxing the ordinary least squares assumption that individuals are independent and identically distributed (Cameron \& Miller, 2015).

Finally, I examine the effect of the mandate repeal on two alternate outcomes - (1) the probability of being newly insured, and (2) the overall probability of being currently uninsured. I do this by estimating a version of the DD regression model described in Eq. (1) in which the outcome variable is NewlyInsured ${ }_{i s t}$, i.e. the probability (ranging from 0 to 100) that respondent $i$ in state $s$ went from being uninsured in the year before the interview $t-1$ to being insured in the year of interview $t$. Next, I estimate Eq. (1) for the outcome variable Uninsured $_{i s t}$, i.e. the probability (ranging from 0 to 100) that respondent $i$ in state $s$ was uninsured in the year of interview $t$. These estimates help me compare my results to those from previous studies that assessed the effect of the implementation of the mandate penalty on insurance coverage.

\section{Results}

I begin by documenting descriptive trends in the outcome variable "Newly Uninsured." Fig. 1 shows that in states where the federal mandate was repealed (treatment states), the probability of being newly uninsured, e.g. having insurance in the year before being interviewed but being uninsured at the time of interview, jumped up to $2.3 \%$ in 2019 . There was substantial state-level variation, and the probability of dropping insurance coverage in 2019

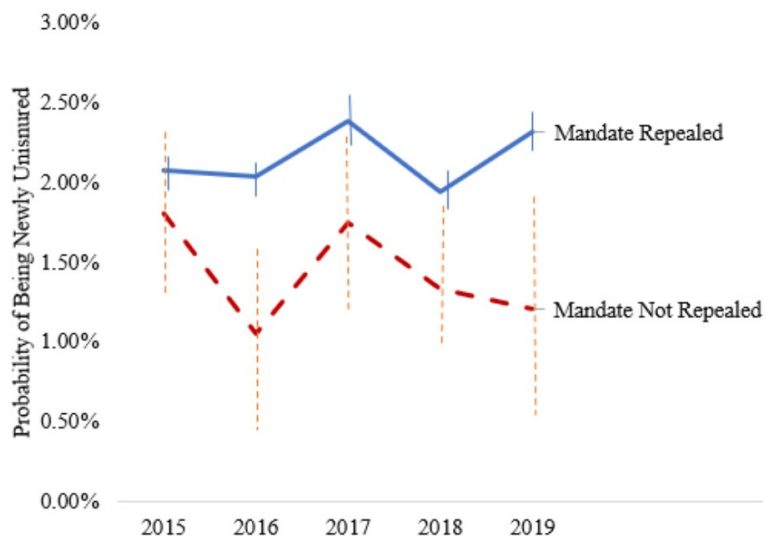

Fig. 1 Probability of being newly uninsured in states with and without an insurance mandate. (Source: Current Population Survey ASEC, 2015 to 2019; Notes: Sample includes adults aged 19 to 64 with household income between 138 and $400 \%$ of the poverty level $(N=214,821)$. Figure displays probability of becoming newly uninsured in 2019, separately for each state. Estimates are weighted by CPS ASEC sampling weights.) 
exceeded 5\% in some states (Appendix Fig. A1). Conversely, in states that had a state-level mandate in place (control states), the probability of being newly uninsured fell in 2019 .

Next, I formalize this relationship by estimating the linear regression described in Eq. (1). Table 1 shows that after controlling for state of residence, year of interview, and socio-demographic characteristics, the repeal of the mandate was associated with a statistically significant $0.496 \%$ point increase in the probability of being newly uninsured. Compared to the pre-2019 mean for treatment states, this represents a $24 \%$ rise in the probability of transitioning to uninsurance. Full regression results are presented in Appendix Table A2.

Event study results presented in Fig. 2 show that treatment and control states followed parallel trends in the pre-2019 period, which support a causal interpretation for the treatment effects estimated in Table $1 .^{3}$ Table 2 presents results from two falsification tests - a sample of elderly adults and a sample of high-income adults - both of whom likely had uninterrupted access to insurance through Medicare and employers during the entirety of the study period and were thus unlikely to respond to the mandate repeal. For both falsification groups, the estimated treatment effect was close to zero and statistically insignificant, which increases our confidence that the treatment and control states did not undergo other differential changes at the same time that the federal mandate was repealed.

In Table 3, I present several sensitivity analyses - including controlling for state unemployment rate, including those below $138 \%$ of the poverty level in the analysis, limiting to states in the New England and mid-Atlantic Census divisions only, and omitting the year 2018 from analysis. My main result is nearly identical across these different specifications. For the baseline model and all four specification checks, the coefficient is about 0.5 and statistically significant at the $1 \%$ level.

I also assess potential heterogeneity by estimating the regression model separately for different subgroups of respondents. Appendix Table A3 shows that the post-repeal increases in uninsurance were driven by those who are not working, those with lower educational

Table 1 Impact of federal insurance mandate repeal on probability of being newly uninsured. (Source: Current Population Survey ASEC, 2015 to 2019)

\begin{tabular}{ll}
\hline & Newly Uninsured \\
\hline Mandate Repealed X Post 2019 & $0.496^{* * *}$ \\
& $(0.175)$ \\
Sample Size & 214,821 \\
Pre-2019 Mean & 2.11 \\
\hline
\end{tabular}

Notes: Sample includes adults aged 19 to 64 with household income between 138 and $400 \%$ of the poverty level $(N=214,821)$. Table displays coefficient estimate and state-clustered standard error for the interaction of an indicator for residence in a state that repealed the insurance mandate and an indicator for the year 2019. All regressions also control for age, sex, marital status, household size, race/ethnicity, educational attainment, employment status, state fixed effects, and year effects. Estimates are weighted by CPS ASEC sampling weights. ${ }^{* * *} p<0.01,{ }^{* *} p<0.05,{ }^{*} p<0.10$

\footnotetext{
${ }^{3}$ It is worth noting that the $95 \%$ confidence interval for the year 2017 is larger than the confidence intervals for other years. While this is likely due to an uptick in the mean and standard deviation of the dependent variable in the year 2017 (see Fig. 1), I interpret the event study result for the year 2017 with caution.
} 


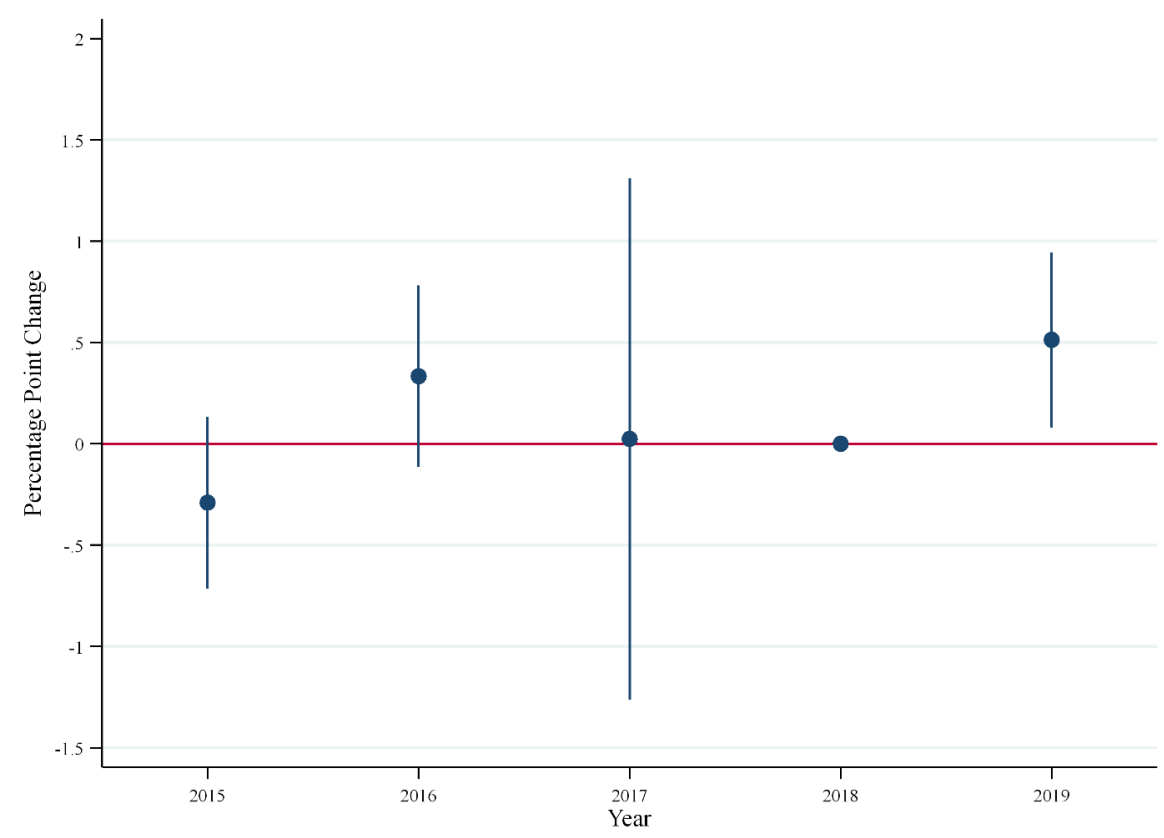

Fig. 2 Differential percentage point change in probability of becoming newly uninsured in repeal states relative to non-repeal states. (Source: Current Population Survey ASEC, 2015 to 2019; Notes: Sample includes adults aged 19 to 64 with household income between 138 and $400 \%$ of the poverty level $(N=214,821)$. Figure displays coefficient estimates and $95 \%$ confidence intervals for a vector of variables interacting the mandate repeal indicator with indicator variables for each year; the 2018 indicator is omitted as the reference period. All regressions also control for age, sex, marital status, household size, race/ethnicity, educational attainment, employment status, state fixed effects, and year effects. Standard errors are clustered by state, and estimates are weighted by CPS ASEC sampling weights.)

Table 2 Falsification tests with alternate samples. (Source: Current Population Survey ASEC, 2015 to 2019)

\begin{tabular}{lll}
\hline & $\begin{array}{l}\text { Elderly } \\
\text { (Age } \\
65+)\end{array}$ & $\begin{array}{l}\text { High- } \\
\text { Income } \\
(>600 \%\end{array}$ \\
& & FPL $)$ \\
\hline Mandate Repeal X Post-2019 & -0.028 & -0.253 \\
& $(0.077)$ & $(0.182)$ \\
Sample Size & 115,772 & 134,114 \\
\hline
\end{tabular}

Notes: Table displays coefficient estimate and state-clustered standard error for the interaction of an indicator for residence in a state that repealed the insurance mandate and an indicator for the year 2019. All regressions also control for age, sex, marital status, household size, race/ethnicity, educational attainment, employment status, state fixed effects, and year effects. Estimates are weighted by CPS ASEC sampling weights.

${ }^{* * *} p<0.01,{ }^{* *} p<0.05,{ }^{*} p<0.10$

attainment, and older adults aged 60 to 64 . Differences along other dimensions-including 
Table 3 Sensitivity analyses. (Source: Current Population Survey ASEC, 2015 to 2019)

\begin{tabular}{llllll}
\hline & Baseline & $\begin{array}{l}\text { Control for State } \\
\text { Unemployment }\end{array}$ & $\begin{array}{l}\text { 0-400\% } \\
\text { FPL } \\
\text { sample }\end{array}$ & $\begin{array}{l}\text { New England } \begin{array}{l}\text { \& Mid-Atlantic } \\
\text { divisions only }\end{array} \\
2018\end{array}$ \\
\hline Mandate Repealed X Post-2019 & $\begin{array}{llll}0.496^{* * *} \\
(0.175)\end{array}$ & $\begin{array}{l}0.503^{* * *} \\
(0.186)\end{array}$ & $\begin{array}{l}0.507^{* * *} \\
(0.164)\end{array}$ & $\begin{array}{l}0.515^{* *} \\
(0.158)\end{array}$ & $\begin{array}{l}0.487^{* *} \\
(0.218)\end{array}$ \\
Sample Size & 214,821 & 214,821 & 296,003 & 29,640 & 174,462 \\
\hline
\end{tabular}

Notes: Unless otherwise indicated, sample includes adults aged 19 to 64 with household income between 138 and $400 \%$ of the poverty level $(N=214,821)$. Table displays coefficient estimate and state-clustered standard error for the interaction of an indicator for residence in a state that repealed the insurance mandate and an indicator for the year 2019. All regressions also control for age, sex, marital status, household size, race/ethnicity, educational attainment, employment status, state fixed effects, and year effects. Estimates are weighted by CPS ASEC sampling weights.

${ }^{* * *} p<0.01,{ }^{* *} p<0.05,{ }^{*} p<0.10$

sex of respondent, parental status, and marital status - were not statistically significant.

Next, I conduct placebo tests with outcome variables that should be theoretically uncorrelated with the mandate repeal—unemployment, self-employment, labor force participa-

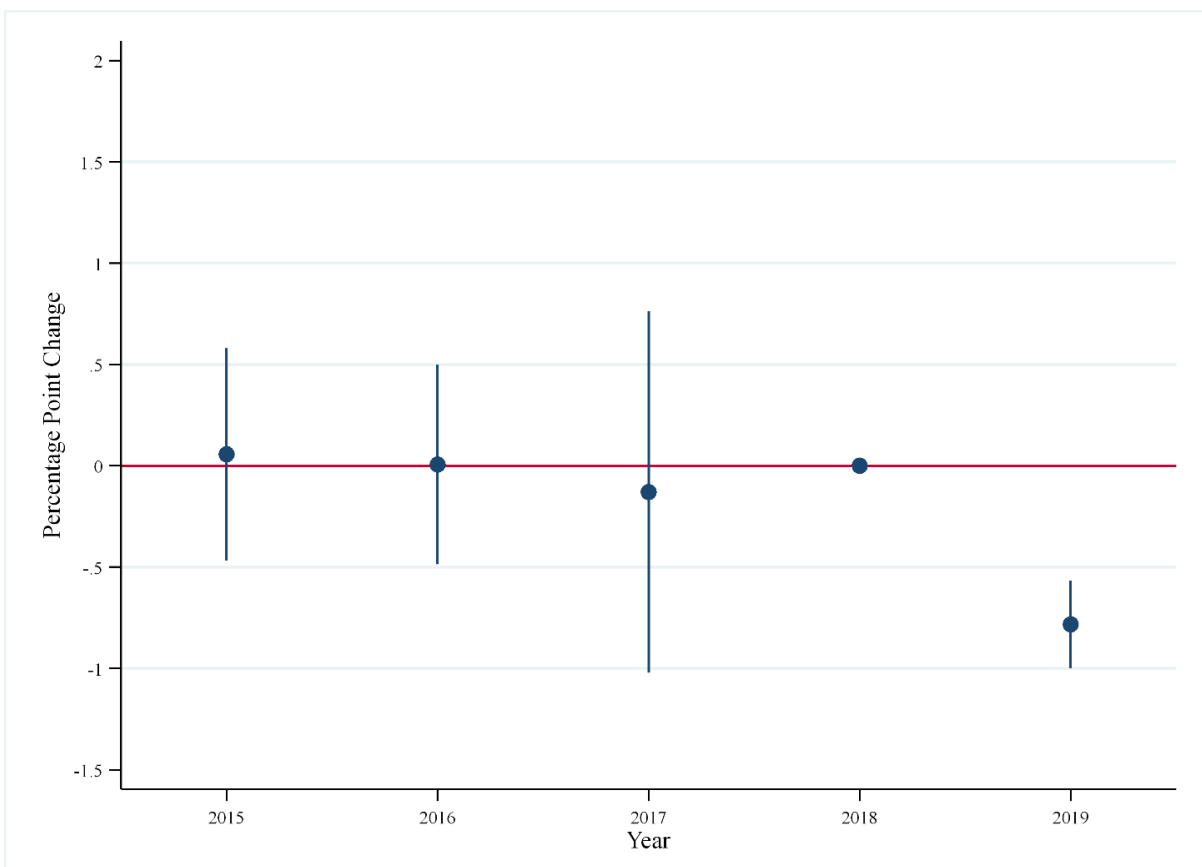

Fig. 3 Differential percentage point change in probability of becoming newly insured in repeal states relative to non-repeal states. (Source: Current Population Survey ASEC, 2015 to 2019; Notes: Sample includes adults aged 19 to 64 with household income between 138 and $400 \%$ of the poverty level $(N=214,821)$. Figure displays coefficient estimates and $95 \%$ confidence intervals for a vector of variables interacting the mandate repeal indicator with indicator variables for each year; the 2018 indicator is omitted as the reference period. All regressions also control for age, sex, marital status, household size, race/ethnicity, educational attainment, employment status, state fixed effects, and year effects. Standard errors are clustered by state, and estimates are weighted by CPS ASEC sampling weights.) 
tion, and household income. As expected, the treatment effects are statistically insignificant for all four placebo outcomes (Appendix Table A4). This finding provides further support for the causal interpretation of the baseline results.

I assess whether results are robust to an alternative method of conducting inference. As shown in Appendix Table A5, using the wild cluster bootstrap procedure to correct standard errors does not affect the interpretation of my key finding. Although the p-value increases slightly after bootstrapping, the main result - that the repeal of the mandate was associated with a $0.496 \%$ point increase in the probability of being newly uninsured - is still statistically significant at the $5 \%$ level.

Finally, Appendix Table A6 shows results from estimating Eq. 1 for two alternate outcome variables - the overall probability of being currently uninsured and the probability of being newly insured. Overall, the mandate repeal led to a $3.3 \%$ point increase $(p<0.01)$ in the probability of being currently uninsured, which is equivalent to a $20 \%$ increase compared to pre-2019 levels. Among my study sample, the repeal of the mandate was associated with a $0.8 \%$ point decrease in the probability of being newly insured in $2019(p<0.01)$, which is equivalent to a $34 \%$ drop compared to previous years. Figure 3 presents event study results for the newly insured outcome. Treatment and control states followed parallel trends in the pre-2019 period, which supports a causal interpretation for my estimated treatment effect. One may be concerned that if individuals anticipated the repeal of the mandate, some may have enrolled in health insurance while the mandate was still in place and consumed all the health care they could afford, and then disenrolled right after the mandate was repealed. However, the event study results presented in Fig. 3 do not suggest anticipatory effects of the repeal on transitions to insurance before 2019 .

\section{Discussion}

This study applies a quasi-experimental approach to provide new evidence on the individual insurance mandate, a policy that has generated considerable controversy. I find that the 2019 repeal of the ACA's individual mandate increased the probability of being newly uninsured by about $0.5 \%$ point, or $24 \%$. A variety of specification checks support a causal interpretation of this estimate. This result suggests that people respond to financial incentives when making insurance enrollment decisions, which is consistent with previous projections predicting coverage reductions as a result of the repeal (Congressional Budget Office, 2019; Glied, 2018).

A previous study of the implementation of the federal insurance mandate by Collins et al. found that the mandate reduced the overall number of uninsured people by $21 \%$ (Collins et al., 2018). The empirical model and outcome variable assessed in Collins et al. are comparable to my supplementary analysis (Appendix Table A6) in which I found that the repeal of the mandate led to a $20 \%$ rise in the number of uninsured people, which is slightly smaller in magnitude than Collins et al.'s estimate. There are several reasons for this asymmetric effect. One possibility may be if government agencies tasked with implementing these policies were more aggressive in informing people about the 2014 implementation of the coverage mandate (to ensure compliance) than about the 2019 repeal of the mandate. If this were the case, people may have been less likely to know about the mandate's repeal and thus less likely to drop coverage in response. However, analysis of Google Trends suggests that 
people were likely well-aware of the mandate's repeal. Appendix Fig. A2 presents trends on US internet searches for the terms "ACA Individual Mandate" and "Individual Mandate Repeal." There was a surge in searches for "Individual Mandate Repeal" in December 2017, around the time the repeal was passed, implying that there was interest in and awareness of the policy change. Moreover, a LexisNexis search of the term "Individual Mandate Repeal" in news articles published between 2017 and 2019 yields over 9,000 results, again suggesting that the repeal was well-publicized.

Another more likely explanation for the asymmetric effect could be inertia, which is substantial in health insurance markets (Handel, 2013; Heiss et al., 2021). Once enrolled in health insurance plans, consumers may be reluctant to drop coverage even if the repeal of the mandate penalty makes it financially beneficial for them to do so. Potential sources of this inertia may include switching costs, inattention, tastes for insurance, and consumers' unwillingness to engage in the hassle of dropping coverage or investigating other insurance options. Thus, once an insurance mandate has been implemented and people have already enrolled in insurance coverage as a response, we would expect consumers to be less responsive to the repeal of the mandate.

Results from heterogeneity tests show that the post-repeal increases in uninsurance were largest among those who were not working (1.0\% point increase for those not working versus statistically insignificant changes for those who were working or self-employed) and those who had a high school education or less $(1.5 \%$ point increase in uninsurance for those with high school education and $1.0 \%$ point increase for those with less than high school education). This suggests that economically vulnerable people respond more to financial incentives when deciding whether to purchase health insurance. The finding is consistent with previous studies which show that people of low socioeconomic status are especially responsive to the penalty (Lurie et al., 2021). The repeal of the penalty likely exacerbated existing socioeconomic disparities in insurance coverage (Sommers et al., 2017). Generally, as socioeconomic status decreases, health outcomes worsen. Future studies may assess whether the removal of low socioeconomic status individuals from insurance plans affects total health care spending among the remaining insured (e.g. by reducing adverse selection) or increases uncompensated care provided by hospitals. It is plausible that aggregate spending may decrease if those who dropped out of insurance coverage were indeed those with worse health and thus more costly for insurers to cover. However, if these individuals continue receiving care but shift their source of care to uncompensated care in emergency room settings, total spending may remain the same or even increase, though the burden of payment would fall on hospitals and governments rather than insurance companies. This is an important question for future research.

Findings should be interpreted in the context of the study's limitations. One limitation is that this paper studies only the first-stage effect of the repeal on uninsurance; future work should analyze downstream effects on access to care and health outcomes. Second, the ASEC's measure of current uninsurance offers a snapshot of insurance status at the time of interview, whereas the question about past year insurance flags respondents as uninsured only if they were uninsured for the entire calendar year. Generally, a higher percentage of people will be uninsured at a point in time than for an entire year, and this may account for some of the observed year-over-year transitions to uninsurance (Stern, 2019). However, my empirical approach relies on comparing the differences in transitions to uninsurance between states that had individual mandates versus those that did not, in post-2019 versus 
pre-2019 years, so this limitation is less concerning for my analysis. Third, as a self-reported survey, the ASEC is subject to item non-response and social desirability bias. However, unless there is reason to expect these biases to correlate systematically with the mandate repeal, they are unlikely to influence my DD estimates.

Another limitation is the use of only one year of data after the repeal of the mandate. Although two years of post-repeal data are available, I do not include 2020 ASEC data in my analysis because the COVID-19 pandemic affected data collection in March and April (https://cps.ipums.org/cps/covid19.shtml). Interviewing began on March 15, but the survey suspended in-person interviewing and closed the two contact centers on March 20. For the remainder of March and April, the survey administrators attempted all interviews by phone. Response rates were about 10\% points lower than the same period in 2019 and previous years. Even more worrisome is the fact that respondents for whom a telephone number was found and were likely to agree to participate in a telephone survey may be systematically different from those for whom a telephone interview could not be secured. Indeed, median income and educational attainment of the 2020 ASEC respondents were higher than those in 2019, suggesting non-random attrition. The 2020 ASEC codebook cautions that, "Data users should exercise caution when comparing estimates for 2020 from the reports or from the microdata files to those from previous years due to the effects that the coronavirus [COVID-19] had on interviewing and response rates" (Current Population Survey, 2021).

A disadvantage to the short-term nature of this study is that the study models a flow (i.e. individuals who become newly uninsured), but an indefinite year-over-year increase in the probability of becoming newly uninsured is unsustainable. The first year of the mandate repeal was likely associated with the largest reduction in insured people, and the number of people to drop coverage likely decreased in subsequent years, as those remaining insured after 2019 would likely be people for whom the benefit of insurance coverage outweighs the cost of the mandate penalty they were previously exposed to. Eventually, the number of people to drop insurance coverage due to the mandate repeal would dwindle down to zero. This study only uses one year of post-repeal data and cannot ascertain the long-term steady state of transitions out of insurance coverage; most likely, my estimate is an upper bound of the steady state. Nevertheless, it is important to understand the short-term effects of the mandate repeal, as losing health insurance can have immediate detrimental effects on access to care, mental health, and health outcomes (Tarazi et al., 2017; Tarazi et al., 2017). Moreover, as the COVID-19 pandemic unfolded just a year after the repeal of the federal insurance mandate, there was widespread concern that the nearly 30 million Americans who lack health insurance coverage would be disproportionately affected by the pandemic (Mota et al., 2020; Rosenbaum \& Handley, 2020). State policymakers can use the results from this study to assess the potential benefits of implementing state-level insurance mandates in the current absence of a federal mandate. Future studies may examine longer-run effects, while carefully controlling for potential confounding effects of the COVID-19 pandemic on insurance coverage.

The findings of this study imply that policies which reduce patients' financial cost of being uninsured may increase uninsurance, which is associated with worse health outcomes (Sommers et al., 2017), increased financial risks of illness (Glied et al., 2020), and higher rates of uncompensated care (Glied, 2018). In the absence of a federal mandate, state-level mandates may reduce transitions to uninsurance. 
Fig. A1 Probability of Becoming Newly Uninsured by State (2019). (Source: Current Population Survey ASEC, 2019; Notes: Sample includes adults aged 19 to 64 with household income between 138 and $400 \%$ of the poverty level $(N=214,821)$. Figure displays probability of becoming newly uninsured in 2019, separately for each state. Estimates are weighted by CPS ASEC sampling weights.)
Probability of Becoming Newly Uninsured By State (2019)

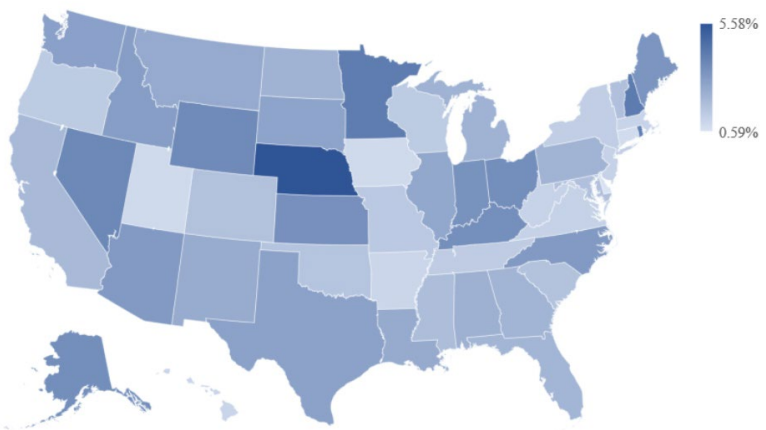

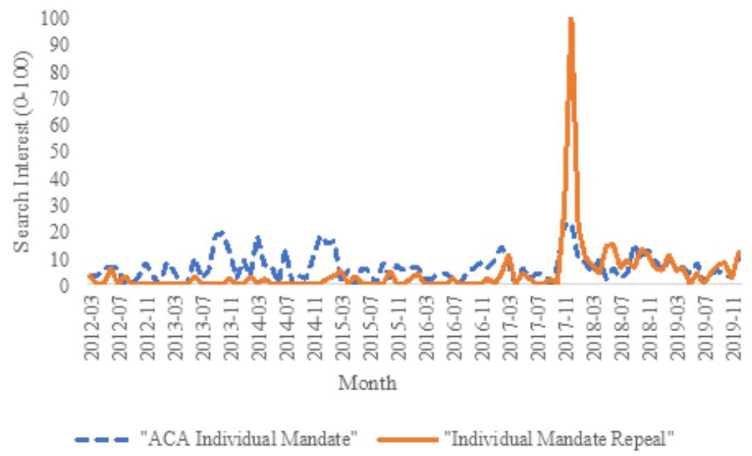

Fig. A2 Google Trends on Internet searches related to aca individual mandate. (Source: Google Trends; Notes: Figure displays Google trends on internet searches for the terms "ACA Individual Mandate" in blue and "Individual Mandate Repeal" in orange. Search interest for a specified term is quantified on a 0 to 100 scale that is normalized to the time period, with 100 representing peak popularity for that search term, relative to all other searches during that period.)

\section{Appendix}

Table A1 Descriptive statistics. (Source: Current Population Survey ASEC, 2015 to 2019)

\begin{tabular}{lllc}
\hline & $\begin{array}{l}\text { Mandate } \\
\text { Repealed (48 } \\
\text { states) }\end{array}$ & $\begin{array}{l}\text { Mandate Not } \\
\text { Repealed (2 states } \\
\text { and DC) }\end{array}$ & Difference \\
\hline Age & 40.00 & 40.52 & $-0.51^{* * *}$ \\
Male & 0.49 & 0.49 & $<0.01$ \\
Married & 0.49 & 0.45 & $0.04^{* * *}$ \\
Household size & 3.34 & 3.39 & $-0.05^{* * *}$ \\
Racelethnicity & & & $0.03^{* * *}$ \\
White, non-Hispanic & 0.55 & 0.52 & $-0.02^{* * *}$ \\
Black, non-Hispanic & 0.14 & 0.16 & $-0.01^{* * *}$ \\
Other, non-Hispanic & 0.08 & 0.09 &
\end{tabular}


Table A1 Descriptive statistics. (Source: Current Population Survey ASEC, 2015 to 2019)

\begin{tabular}{|c|c|c|c|}
\hline & $\begin{array}{l}\text { Mandate } \\
\text { Repealed (48 } \\
\text { states) }\end{array}$ & $\begin{array}{l}\text { Mandate Not } \\
\text { Repealed ( } 2 \text { states } \\
\text { and DC) }\end{array}$ & Difference \\
\hline Hispanic & 0.23 & 0.23 & $<0.01$ \\
\hline \multicolumn{4}{|l|}{ Educational attainment } \\
\hline Less than high school & 0.12 & 0.09 & $0.03^{* * *}$ \\
\hline High school & 0.35 & 0.36 & $-0.01^{*}$ \\
\hline Some college & 0.33 & 0.29 & $0.04^{* * *}$ \\
\hline College or more & 0.20 & 0.26 & $-0.06^{* * *}$ \\
\hline \multicolumn{4}{|l|}{ Employment status } \\
\hline Working but not self-employed & 0.69 & 0.69 & $<0.01$ \\
\hline Self-employed & 0.06 & 0.06 & $0.01^{* * *}$ \\
\hline Not working & 0.25 & 0.26 & $-0.01^{*}$ \\
\hline Observations & 205,944 & 8,877 & \\
\hline
\end{tabular}

Notes: Sample includes adults aged 19 to 64 with household income between 138 and $400 \%$ of the poverty level $(N=214,821)$. Table displays means adjusted by CPS ASEC sampling weights.

${ }^{* * *} p<0.01,{ }^{* *} p<0.05,{ }^{*} p<0.10$

Table A2 Full regression results. (Source: Current Population Survey ASEC, 2015 to 2019)

\begin{tabular}{|c|c|}
\hline & $\begin{array}{l}\text { Newly } \\
\text { Uninsured }\end{array}$ \\
\hline Mandate Repealed X Post 2019 & $\begin{array}{l}0.4963^{* * *} \\
(0.1748)\end{array}$ \\
\hline Age & $\begin{array}{l}-0.0356^{* * *} \\
(0.0032)\end{array}$ \\
\hline Male & $\begin{array}{l}-0.1744^{* *} \\
(0.0728)\end{array}$ \\
\hline Married & $\begin{array}{c}-0.1658 \\
(0.1078)\end{array}$ \\
\hline Household Size & $\begin{array}{l}-0.1118^{* * *} \\
(0.0333)\end{array}$ \\
\hline \multicolumn{2}{|l|}{ Race/Ethnicity } \\
\hline White, non-Hispanic & - \\
\hline Black, non-Hispanic & $\begin{array}{l}0.4162^{* *} \\
(0.1572)\end{array}$ \\
\hline Other, non-Hispanic & $\begin{array}{l}0.1518 \\
(0.1140)\end{array}$ \\
\hline Hispanic & $\begin{array}{l}0.1707 \\
(0.1482)\end{array}$ \\
\hline \multicolumn{2}{|l|}{ Educational Attainment } \\
\hline Less than high school & $\begin{array}{c}-0.0859 \\
(0.1277)\end{array}$ \\
\hline High school & - \\
\hline Some college & $\begin{array}{l}-0.1986^{*} \\
(0.1079)\end{array}$ \\
\hline College or more & $\begin{array}{l}-0.6960^{* * *} \\
(0.0885)\end{array}$ \\
\hline \multicolumn{2}{|l|}{ Employment Status } \\
\hline Working but not self-employed & - \\
\hline Self-employed & $\begin{array}{l}0.8701^{* * *} \\
(0.1565)\end{array}$ \\
\hline
\end{tabular}


Table A2 Full regression results. (Source: Current Population Survey ASEC, 2015 to 2019)

\begin{tabular}{ll}
\hline & Newly \\
Not working & Uninsured \\
\hline Sample Size & $-0.2683^{* * *}$ \\
Pre-2019 Mean & $(0.0800)$ \\
\hline
\end{tabular}

Notes: Sample includes adults aged 19 to 64 with household income between 138 and $400 \%$ of the poverty level $(N=214,821)$. Table displays coefficient estimate and state-clustered standard error. All regressions also control for state fixed effects and year effects. Estimates are weighted by CPS ASEC sampling weights. ${ }^{* * *} p<0.01,{ }^{* *} p<0.05,{ }^{*} p<0.10$

Table A3 Heterogeneity tests. (Source: Current Population Survey ASEC, 2015 to 2019)

\begin{tabular}{|c|c|c|c|}
\hline & $\begin{array}{l}\text { Mandate Repealed X Post } \\
2019\end{array}$ & Sample Size & $\begin{array}{l}\text { Pre-2019 } \\
\text { Mean for } \\
\text { Treatment } \\
\text { Group }\end{array}$ \\
\hline Pooled Sample & $\begin{array}{l}0.496^{* * *} \\
(0.175)\end{array}$ & 214,821 & 2.11 \\
\hline \multicolumn{4}{|l|}{ By $\operatorname{Sex}$} \\
\hline Male & $\begin{array}{l}0.494^{* *} \\
(0.221)\end{array}$ & 102,648 & 2.09 \\
\hline Female & $\begin{array}{l}0.482^{* * *} \\
(0.176)\end{array}$ & 112,173 & 2.12 \\
\hline \multicolumn{4}{|l|}{ By Marital Status } \\
\hline Married & $\begin{array}{l}0.416^{* *} \\
(0.168)\end{array}$ & 114,278 & 1.90 \\
\hline Not Married & $\begin{array}{l}0.597^{* *} \\
(0.252)\end{array}$ & 100,543 & 2.30 \\
\hline \multicolumn{4}{|l|}{ By Parental Status } \\
\hline Parents & $\begin{array}{l}0.678^{* * *} \\
(0.202)\end{array}$ & 117,373 & 2.00 \\
\hline Childless Adults & $\begin{array}{l}0.305 \\
(0.354)\end{array}$ & 97,448 & 2.20 \\
\hline \multicolumn{4}{|l|}{ By Employment Status } \\
\hline Working but not self-employed & $\begin{array}{l}0.277 \\
(0.320)\end{array}$ & 149,649 & 2.18 \\
\hline Self-employed & $\begin{array}{l}0.233 \\
(1.146)\end{array}$ & 13,979 & 2.81 \\
\hline Not working & $\begin{array}{l}1.047^{* * *} \\
(0.224)\end{array}$ & 51,193 & 1.73 \\
\hline \multicolumn{4}{|l|}{ By Educational Attainment } \\
\hline Less than high school & $\begin{array}{l}0.997^{* * *} \\
(0.331)\end{array}$ & 26,368 & 2.07 \\
\hline High school & $\begin{array}{l}1.461^{* *} \\
(0.627)\end{array}$ & 73,869 & 2.31 \\
\hline Some college & $\begin{array}{l}-1.346^{*} \\
(0.744)\end{array}$ & 70,456 & 2.20 \\
\hline College or more & $\begin{array}{l}0.731^{* *} \\
(0.307)\end{array}$ & 44,128 & 1.63 \\
\hline \multicolumn{4}{|l|}{ By Race/Ethnicity } \\
\hline White, non-Hispanic & $\begin{array}{l}1.281^{* * *} \\
(0.418)\end{array}$ & 115,269 & 2.07 \\
\hline
\end{tabular}


Table A3 Heterogeneity tests. (Source: Current Population Survey ASEC, 2015 to 2019)

\begin{tabular}{|c|c|c|c|}
\hline & $\begin{array}{l}\text { Mandate Repealed X Post } \\
2019\end{array}$ & Sample Size & $\begin{array}{l}\text { Pre-2019 } \\
\text { Mean for } \\
\text { Treatment } \\
\text { Group }\end{array}$ \\
\hline Black, non-Hispanic & $\begin{array}{l}-1.036^{* *} \\
(0.495)\end{array}$ & 27,622 & 2.40 \\
\hline Other, non-Hispanic & $\begin{array}{l}2.436^{* * *} \\
(0.470)\end{array}$ & 19,781 & 1.90 \\
\hline Hispanic & $\begin{array}{l}-1.044^{* * *} \\
(0.232)\end{array}$ & 52,149 & 2.10 \\
\hline \multicolumn{4}{|l|}{ By Age } \\
\hline $19-26$ & $\begin{array}{l}1.817^{*} \\
(1.062)\end{array}$ & 39,046 & 2.64 \\
\hline $27-39$ & $\begin{array}{l}-1.113 \\
(0.812)\end{array}$ & 68,701 & 2.49 \\
\hline $40-49$ & $\begin{array}{l}0.094 \\
(0.387)\end{array}$ & 47,667 & 1.83 \\
\hline $50-59$ & $\begin{array}{l}0.581 \\
(0.351)\end{array}$ & 40,863 & 1.55 \\
\hline $60-64$ & $\begin{array}{l}2.893^{* * *} \\
(0.458)\end{array}$ & 18,544 & 1.49 \\
\hline
\end{tabular}

Notes: Sample includes adults aged 19 to 64 with household income between 138 and $400 \%$ of the poverty level $(N=214,821)$. Table displays coefficient estimate and state-clustered standard error for the interaction of an indicator for residence in a state that repealed the insurance mandate and an indicator for the year 2019. All regressions also control for age, sex, marital status, household size, race/ethnicity, educational attainment, employment status, state fixed effects, and year effects. Estimates are weighted by CPS ASEC sampling weights.

${ }^{* * *} p<0.01,{ }^{* *} p<0.05,{ }^{*} p<0.10$

Table A4 Placebo tests with alternate outcomes. (Source: Current Population Survey ASEC, 2015 to 2019)

\begin{tabular}{lllll}
\hline & Unemployed & Self-employed & $\begin{array}{l}\text { In labor } \\
\text { force }\end{array}$ & $\begin{array}{l}\text { House- } \\
\text { hold } \\
\text { income }\end{array}$ \\
\hline Mandate Repealed X Post-2019 & 0.453 & 0.403 & 0.319 & 89.752 \\
Sample Size & $(0.429)$ & $(0.799)$ & $(0.328)$ & $(371.577)$ \\
& 132,168 & 133,034 & 173,180 & 174,462 \\
\hline
\end{tabular}

Notes: Sample includes adults aged 19 to 64 with household income between 138 and $400 \%$ of the poverty level $(N=214,821)$. Table displays coefficient estimate and state-clustered standard error for the interaction of an indicator for residence in a state that repealed the insurance mandate and an indicator for the year 2019. All regressions also control for age, sex, marital status, household size, race/ethnicity, educational attainment, employment status, state fixed effects, and year effects. Estimates are weighted by CPS ASEC sampling weights.

${ }^{* * *} p<0.01,{ }^{* *} p<0.05,{ }^{*} p<0.10$ 
Table A5 Bootstrapped standard errors. (Source: Current Population Survey ASEC, 2015 to 2019)

\begin{tabular}{|c|c|}
\hline & $\begin{array}{l}\text { Newly } \\
\text { Uninsured }\end{array}$ \\
\hline Mandate Repealed X Post 2019 & $\begin{array}{l}0.496^{* *} \\
(0.036)\end{array}$ \\
\hline Sample Size & 214,821 \\
\hline Pre-2019 Mean & 2.11 \\
\hline
\end{tabular}

Notes: Sample includes adults aged 19 to 64 with household income between 138 and $400 \%$ of the poverty level $(N=214,821)$. Table displays coefficient estimate and adjusted p-values for the interaction of an indicator for residence in a state that repealed the insurance mandate and an indicator for the year 2019. All regressions also control for age, sex, marital status, household size, race/ethnicity, educational attainment, employment status, state fixed effects, and year effects. Estimates are weighted by CPS ASEC sampling weights. Adjusted p-values are calculated using a wild cluster bootstrap procedure.

${ }^{* * *} p<0.01,{ }^{* *} p<0.05,{ }^{*} p<0.10$

Table A6 Alternate outcomes. (Source: Current Population Survey ASEC, 2015 to 2019)

\begin{tabular}{lll}
\hline & Newly Insured & $\begin{array}{l}\text { Currently } \\
\text { Uninsured }\end{array}$ \\
\hline Mandate Repealed X Post 2019 & $0.767^{* * *}$ & $3.288^{* * *}$ \\
Sample Size & $(0.185)$ & $(0.503)$ \\
Pre-2019 Mean & 214,821 & 214,821 \\
\hline
\end{tabular}

Notes: Sample includes adults aged 19 to 64 with household income between 138 and $400 \%$ of the poverty level $(N=214,821)$. Table displays coefficient estimate and state-clustered standard errors for the interaction of an indicator for residence in a state that repealed the insurance mandate and an indicator for the year 2019. All regressions also control for age, sex, marital status, household size, race/ethnicity, educational attainment, employment status, state fixed effects, and year effects. Estimates are weighted by CPS ASEC sampling weights.

${ }^{* * *} p<0.01,{ }^{* *} p<0.05,{ }^{*} p<0.10$.

Acknowledgements I thank Chloe East for helpful comments and Colleen Mattingly and Alexandra Rakus for excellent research assistance.

Funding Sources N/A.

\section{Disclosure}

Ethical Statement No human subjects were recruited or analyzed in this study, and all data used are publicly available.

Conflict of Interest Statement The author has no known conflict of interest regarding the subject of this paper.

\section{References}

Abramowitz, J., \& O’Hara, B. (2017). New Estimates of Offer and Take-Up of Employer-Sponsored Insurance. Medical Care Research and Review, 74(5), 595-612. https://doi.org/10.1177/1077558716654630

Cameron, A. C., Gelbach, J. B., \& Miller, D. L. (2008). Bootstrap-Based Improvements for Inference with Clustered Errors. Review of Economics and Statistics, 90(3), 414-427. https://doi.org/10.1162/ rest.90.3.414

Colin Cameron, A., \& Miller, D. L. (2015). A Practitioner's Guide to Cluster-Robust Inference. Journal of Human Resources, 50(2), 317-372. https://doi.org/10.3368/jhr.50.2.317 
Collins, S. R., Gunja, M. Z., Doty, M. M., \& Bhupal, H. K. (2018). First Look at Health Insurance Coverage in 2018 Finds ACA Gains Beginning to Reverse

Congressional Budget Office (2019). Federal Subsidies for Health Insurance Coverage for People Under Age 65: 2019 to 2029. Retrieved from https://www.cbo.gov/system/files/2019-05/55085-HealthCoverageSubsidies 0.pdf

Current Population Survey (2021). 2020 Annual Social and Economic (ASEC) Supplement. Retrieved from https://cps.ipums.org/cps/resources/codebooks/cpsmar20.pdf

Ferman, B., \& Pinto, C. (2019). Inference in Differences-in-Differences with Few Treated Groups and Heteroskedasticity. The Review of Economics and Statistics, 101(3), 452-467. https://doi.org/10.1162/ rest_a_00759

Fiedler, M. (2018). How did the ACA's individual mandate affect insurance coverage? Evidence from coverage decisions by higher income people. Retrieved from https://www.brookings.edu/research/ how-did-the-acas-individual-mandate-affect-insurance-coverage-evidence-from-coverage-decisionsby-higher-income-people/

Fiedler, M. (2020). The ACA's Individual Mandate In Retrospect: What Did It Do, And Where Do We Go From Here? Health Affairs, 39(3), 429-435. https://doi.org/10.1377/hlthaff.2019.01433

Flood, S., King, M., Rodgers, R., Ruggles, S., \& Warren, J. R. (2020). Integrated Public Use Microdata Series, Current Population Survey: Version 7.0 [dataset]. Retrieved from https://doi.org/10.18128/ D030.V7.0

Fung, V., Liang, C. Y., Shi, J., Seo, V., Overhage, L., Dow, W. H. ... Hsu, J. (2019). Potential Effects Of Eliminating The Individual Mandate Penalty In California. Health Affairs, 38(1), 147-154. https://doi. org/10.1377/hlthaff.2018.05161

Glied, S. (2018). Implications of the 2017 Tax Cuts and Jobs Act for Public Health. American Journal of Public Health, 108(6), 734-736. https://doi.org/10.2105/AJPH.2018.304388

Glied, S., Collins, S. R., \& Lin, S. (2020). Did The ACA Lower Americans' Financial Barriers To Health Care? Health Affairs, 39(3), 379-386. https://doi.org/10.1377/hlthaff.2019.01448

Handel, B. R. (2013). Adverse Selection and Inertia in Health Insurance Markets: When Nudging Hurts. American Economic Review, 103(7), 2643-2682. https://doi.org/10.1257/aer.103.7.2643

Heiss, F., McFadden, D., Winter, J., Wuppermann, A., \& Zhou, B. (2021). Inattention and Switching Costs as Sources of Inertia in Medicare Part D. American Economic Review, 111(9), 2737-2781. https://doi. org/10.1257/aer.20170471

Jacobs, P. D. (2018). Mandating Health Insurance Coverage for High-Income Individuals. National Tax Journal, 71(4), 807-828. https://doi.org/10.17310/ntj.2018.4.10

Kaestner, R., Garrett, B., Chen, J., Gangopadhyaya, A., \& Fleming, C. (2017). Effects of ACA Medicaid Expansions on Health Insurance Coverage and Labor Supply. Journal of Policy Analysis and Management, 36(3), 608-642. https://doi.org/10.1002/pam.21993

Keith, K. (2020). Tracking The Uninsured Rate In 2019 And 2020. In Health Affairs Blog. Retrieved from https:/www.healthaffairs.org/do/10.1377/hblog20201007.502559/full/

Lurie, I. Z., Sacks, D. W., \& Heim, B. (2021). Does the Individual Mandate Affect Insurance Coverage? Evidence from Tax Returns. American Economic Journal: Economic Policy, 13(2), 378-407. https:// doi.org/10.1257/pol.20180619

Mota, A. B., Fei, S., \& Stiers, K. (2020, June 24). Rising uninsurance is taking this pandemic from bad to worse. USC Annenberg Center for Health Journalism. Retrieved from https://centerforhealthjournalism.org/2020/06/19/rising-uninsurance-taking-pandemic-bad-worse\#: :text=Rising uninsurance is taking this pandemic from bad to worse,-By Andrea Banuelos\&text=In the three months since,have filed new unemployment claims.\&text=

Pascale, J. (2016). Modernizing a Major Federal Government Survey: A Review of the Redesign of the Current Population Survey Health Insurance Questions. Journal of Official Statistics, 32(2), 461-486. https://doi.org/10.1515/jos-2016-0024

Pascale, J., Boudreaux, M., \& King, R. (2016). Understanding the New Current Population Survey Health Insurance Questions. Health Services Research, 51(1), 240-261. https://doi.org/10.1111/1475-6773.12312

Pascale, J., Fertig, A., \& Call, K. (2019). Validation of Two Federal Health Insurance Survey Modules After Affordable Care Act Implementation. Journal of Official Statistics, 35(2), 409-460. https://doi. org/10.2478/jos-2019-0019

Porretta,A.(2021). Does Your State Require Youto Have Health Insurance? Retrieved from https://www.ehealthinsurance.com/resources/individual-and-family/does-your-state-require-you-to-have-health-insurance

Rosenbaum, S., \& Handley, M. (2020). Caring for the Uninsured in a Pandemic Era. In Assessing Legal Responses to COVID-19. Boston

Saltzman, E. (2019). Demand for health insurance: Evidence from the California and Washington ACA exchanges. Journal of Health Economics, 63, 197-222. https://doi.org/10.1016/j.jhealeco.2018.11.004 
Sommers, B. D., Gawande, A. A., \& Baicker, K. (2017). Health Insurance Coverage and Health - What the Recent Evidence Tells Us. New England Journal of Medicine, 377(6), 586-593. https://doi.org/10.1056/ NEJMsb1706645

Sommers, B. D., McMurtry, C. L., Blendon, R. J., Benson, J. M., \& Sayde, J. M. (2017). Beyond Health Insurance: Remaining Disparities in US Health Care in the Post-ACA Era. Milbank Quarterly, 95(1), 43-69. https://doi.org/10.1111/1468-0009.12245

Stern, S. (2019). Current Coverage, Calendar-Year Coverage: Two Measures, Two Concepts. Retrieved from https://www.census.gov/newsroom/blogs/research-matters/2019/09/current-coverage.html

Tarazi, W. W., Bradley, C. J., Bear, H. D., Harless, D. W., \& Sabik, L. M. (2017). Impact of Medicaid disenrollment in Tennessee on breast cancer stage at diagnosis and treatment. Cancer, 123(17), 3312-3319. https://doi.org/10.1002/cncr.30771

Tarazi, W. W., Green, T. L., \& Sabik, L. M. (2017). Medicaid Disenrollment and Disparities in Access to Care: Evidence from Tennessee. Health Services Research, 52(3), 1156-1167. https://doi. org/10.1111/1475-6773.12515

Wagner, K. L. (2015). Medicaid Expansions for the Working Age Disabled: Revisiting the Crowd-Out of Private Health Insurance. Journal of Health Economics, 40(March), 69-82. https://doi.org/10.1016/j. jhealeco.2014.12.007

Young, J. (2009, September 22). Kyl: Health bill a "stunning assault on liberty." The Hill. Retrieved from https://thehill.com/blogs/blog-briefing-room/news/59761-kyl-health-bill-a-stunning-assault-on-liberty-

Publisher's Note Springer Nature remains neutral with regard to jurisdictional claims in published maps and institutional affiliations. 